\title{
Desafios contemporâneos da Atenção Primária à Saúde
}

Helvécio Miranda Magalhães Júnior

\section{RESUMO}

Artigo elaborado a partir de conferência realizada na 1a Oficina da Rede APS 2019, em março de 2019 na FACE/UFMG, que realizou balanço da trajetória da Atenção Primária em Saúde (APS) e muito menos do Sistema Único de Saúde (SUS) neste seu avançar após os 30 anos da Constituição Federal de 1988. Para abordar os desafios atuais da APS, foi necessário um rápido repasse deste caminhar até o momento atual. A implementação do SUS, desde os seus primeiros passos, se deu concomitante a um novo papel para os municípios brasileiros, também nascidos como entes federados na mesma Constituição e à expansão de cobertura assistencial, em especial da atenção básica ou primária, já em curso desde os movimentos pré SUS.

Palavras-chave: Atenção Primária à Saúde, Saúde Pública, Financiamento da APS.

Revista da Rede APS 2019

Publicada em: 17/12/2019

DOI:10.14295/aps.v1i3.47

Helvecio Miranda Magalhães Júnior

(Fiocruz-Minas e

FELUMA/Faculdade de Ciências Médicas de Minas Gerais, Brasil)

Correspondência para: Helvécio Miranda Magalhães Júnior

helveciomiranda@gmail.com 


\section{DebateS E Discussões}

\section{APS em Revista}

Vol. 1, n. 3, p. 222/229 | Setembro/Dezembro - 2019

ISSN 2596-3317 - DOI 10.14295/aps.v1i3.47

Magalhães Júnior, H. M.

\section{Debates e DISCUSsõES}

Não é objetivo deste texto fazer um balanço exaustivo da trajetória da APS - Atenção Primária em Saúde e muito menos do Sistema Único de Saúde -SUS neste seu avançar após os 30 anos da CF de 1988. Entretanto, para abordar os desafios atuais da APS, é necessário um rápido repasse deste caminhar até o momento atual. A implementação do SUS, desde os seus primeiros passos, se deu concomitante a um novo papel para os municípios brasileiros, também nascidos como entes federados na mesma Constituição e à expansão de cobertura assistencial, em especial da atenção básica ou primária, já em curso desde os movimentos pré SUS. A partir de 1994, com o formato do PSF - Programa de Saúde da Família e dos ACS- Agentes Comunitários de Saúde, sustentado por experiências internacionais e iniciativas de vários municípios brasileiros, tudo isto corolário da trajetória, ainda que com idas e vindas, do movimento sanitário brasileiro.

Esta brevíssima histórico é importante, por deixar como imagem um vetor de sempre crescimento da APS no país, em diferentes modalidades, com variadas tecnologias e potências, mas, progressivamente vertebrada a partir da Estratégia de Saúde da Família. Fato é que as robustas evidências internacionais e resultados de investigações no Brasil demonstram a capacidade estruturante da APS na efetivação do SUS como um real sistema universal de saúde para os brasileiros, com a adicional vantagem de torná-lo mais eficiente e efetivo, ademais, melhorar a satisfação percebida pelos usuários. Visão esta que vem sendo incorporada ao sistema privado de assistência à saúde, algumas décadas atrasadas em relação ao público.

Sendo assim, por que a APS e, por conseguinte, o SUS não conseguem ainda ser o sistema ou serviço do coração da imensa maioria da população? Por que há ainda o sonho de consumo da aquisição de planos privados de assistência, mesmo que também estes muito mal avaliados como regra na satisfação dos seus clientes, em patamares às vezes semelhantes aos do SUS e com muito menor demanda e escopo de atuação. Por que, há este sentimento de insuficiência de resposta os serviços de APS, por que tanta queixa dos usuários, por que da não consecução da premissa de ser a APS a estruturadora da rede de serviços do SUS e sua principal porta de entrada. Por que do seu ainda baixo reconhecimento social, nos resultados inquestionáveis no quadro de saúde e do efeito concreto de seus milhões de atendimentos? A sensação de estarmos no caminho certo de optar por ter a APS sempre como foco principal da atuação política e gestora do sistema de saúde nos exige cada vez mais reflexões qualificadas sobre seus desafios e estes devem ser o pano de fundo para a implementação de pesquisas neste campo no Brasil.

O caso de Belo Horizonte é exemplar, foram décadas de persistência na organização do SUS e da APS na cidade, de forma sustentada e passando por diversos governos diferentes, com clareza do papel gestor, primeira grande cidade a assumir a gestão plena do SUS na década de 1990, com ousada iniciativa de implantar pioneiramente em termos de grandes capitais, a estratégia de saúde da família com ampla cobertura, com grande escopo de cuidado, com articulação dos demais pontos de atenção da rede para a sua sustentação. Apesar disso, há uma inquietação de sua equipe dirigente e técnica de onde avançar, para onde seguir, como intervir nas lacunas de satisfação dos usuários, como garantir qualidade efetiva, como enfrentar uma certa hegemonia dos nãos aos usuários ou uma burocratização da atenção. Este sentimento certamente permeia várias das gestões municipais hoje, incluindo os desafios de organização das regiões de saúde que teimam em não ser organizadas de fato. Mas esta é outra conversa, ainda que necessária.

E no corrente ano, este esforço de todo o movimento social da saúde, gestores, trabalhadores, usuários e acadêmicos, é ainda maior pela conjuntura adversa liderada pelo atual governo federal, sugere um certo questionamento ao conjunto dos direitos arduamente conquistados pela população brasileira, e à presença de um Estado mais ativo na condução de políticas 


\section{DebateS E Discussões}

\section{APS em Revista}

Vol. 1, n. 3, p. 222/229 | Setembro/Dezembro - 2019

ISSN 2596-3317 - DOI 10.14295/aps.v1i3.47

Magalhães Júnior, H. M.

produtoras de igualdade, aí incluídos os direitos humanos e os coletivos à saúde e à educação, com destaque para o mundo da ciência e tecnologia. Pouca clareza de políticas públicas consistentes e, às vezes contraditórias, que façam avançar o jovem SUS. Neste cenário incerto, os desafios são ainda maiores para este conjunto de forças interessadas realmente nos não retrocessos e no fortalecimento progressivo do SUS: perseverar na reflexão, formulação e inciativas, quando há tanto a defender de conquistas anteriores no campo dos direitos humanos e difusos, incluindo a saúde pública.

Como forma de organizar a reflexão, ainda que algo artificial pelas suas interfaces, vamos organizar os desafios em três eixos: os recursos (financiamento e sustentabilidade), as pessoas (recursos humanos e seus dilemas) e o jeito de atender (modelo de atenção e de organização).

Este primeiro elemento, o do financiamento pode ter dois enfoques. O primeiro é o que já pode ser chamado de desfinanciamento do conjunto do SUS que vem desde a EC - Emenda Constitucional 95. A luta desde a CF - Constituição Federal - de 1988 para que o SUS tivesse um financiamento adequado e sustentável, mesmo com vitórias e derrotas, vinha em uma trajetória ascendente, com a EC 29, a Lei Complementar 141 e até a EC 86, que cravaram critérios e parâmetros de financiamento para o SUS nas três esferas de governo, ainda que claramente insuficientes. Com a EC 95, a curva se inverte e faz uma inflexão negativa, como estudos brasileiros e internacionais vem demonstrando, com os efeitos a médio e longo prazo, da chamada austeridade fiscal. A curto prazo, no orçamento do MS para este ano e os próximos, existem perdas da ordem dos bilhões, saindo entre 2017 e 2020, de 119,5 bilhões para 113,1 bilhões.

Esta referência é importante porque é muito improvável que, com este horizonte de desfinanciamento por parte do Governo Federal, ente que reduziu progressivamente nas últimas duas décadas sua participação relativa nos recursos públicos da saúde, haja espaço para uma melhoria significativa, por melhor que seja a boa intenção das equipes técnicas. E para 2020, segundo o PLOA apresentado pelo Governo ao Congresso Nacional, tem por volta de 20 bilhões a menor do que seria se não existisse a EC 95. Pior, mesmo com eventuais acréscimos da receita, como o bilionário bônus do próximo leilão do pré-sal, a rigidez da emenda 95 não deixa nenhum ganho adicional para a saúde e as demais despesas, porque estão lastreadas em 15\% da RCL - Receita Corrente Líquida de 2017. Além disto, o PLOA na saúde traz um contingenciamento previsto de 32,5 bilhões, vinculado a créditos adicionais a serem aprovados por conta da chamada Regra de Ouro do orçamento público. Verdade também que o orçamento da APS tem uma projeção de incremento em relação a 2019 de mais de três bilhões, a conferir na aprovação do projeto e na sua execução no decorrer do ano.

A seguir, o financiamento específico da APS. Esta tem crescido em termos reais nas últimas décadas, coerente com a expansão ocorrida, sempre com grande participação municipal. Como exemplo, no ciclo de 2011 a 2014, o orçamento do MS cresceu em termos nominais mais de $100 \%$, com ênfase em mecanismos de transferência baseados em critérios de cobertura (expansão do PAB variável, condições estruturais (Requalifica $A B$ e E-SUS $A B$ ) e eficiência e da qualidade (PMAQ - Programa de Melhoria do Acesso e Qualidade). Mesmo com estes avanços, o componente federal do financiamento da APS, continuou a ser insuficiente para a aposta de estruturar a APS dos sonhos, seja em relação a infraestrutura material e tecnológica, seja em termos de composição ampliada de equipes; o que vem sobrecarregando os municípios, até porque a participação do nível estadual é, ainda que crescente, pequena e desigual.

Um debate importante é o formato de transferência por blocos, que deixou de blindar a APS com uma mudança em 2017, mas que trouxe outros ganhos em termos de melhor utilização dos recursos transferidos a estados e municípios. No momento está também em discussão uma nova proposta de financiamento da APS por parte da recém-criada Secretaria de Atenção Primária à Saúde, idéia gerada em 2008 a partir de discussão do MS com o CONASEMS e agora viabilizada, o que deve ser considerado um potencial avanço. Esta proposta precisa ser profundamente debatida, também 


\section{DebateS E Discussões}

\section{APS em Revista}

Vol. 1, n. 3, p. 222/229 | Setembro/Dezembro - 2019

ISSN 2596-3317 - DOI 10.14295/aps.v1i3.47

Magalhães Júnior, H. M.

porque tem relação direta com os dois desafios que serão abordados a seguir. Primeiro o provimento de profissionais, com dois aspectos centrais, o provimento do profissional médico da APS e os estímulos à prática do conceito ampliado de equipes multiprofissionais; segundo com o modelo de atenção e gestão.

O segundo grande desafio da APS e do SUS em geral é o provimento adequado e suficiente de profissionais. Sendo a saúde um setor de serviços intensivo em mão de obra nos conceitos econômicos, este dilema é central e se tornou uma das fraquezas e insuficiências do SUS desde sempre. Há evidências fortes de um descompasso entre a aposta do SUS com oferta de serviços de saúde de diferentes densidades tecnológicas e largo escopo, na busca do cumprimento do princípio constitucional da integralidade e a formação, técnica e profissional, dos trabalhadores. A premissa de ser uma função do SUS e do MS a ordenação da formação dos profissionais da saúde nunca foi efetivada. Um exemplo claro é a permanência, desde a sua criação no período da ditadura militar, da Comissão Nacional de Residência Médica no Ministério da Educação e com participação minoritária dos gestores da saúde. E aí, diversas contradições vem ocorrendo, em que pese várias iniciativas de mudanças curriculares e de orientação para a formação dos recursos humanos em saúde. Uma exceção foi o esforço monumental feito no país para a profissionalização dos profissionais técnicos da enfermagem que incluiu a necessidade de escolarização em larga escala.

Neste campo, dentre outros, dois problemas se sobressaem. Um, a questão dos profissionais médicos, que são trabalhadores que têm características muito próprias da sua atuação, seja pela legitimidade social historicamente construída a partir de um processo elitista de sua formação e da própria sociedade, seja pelo cada vez mais longo tempo de terminalidade real da formação universitária e os derivados programas de residência médica, seja pela valorização no mercado de trabalho. Bom lembrar que, mesmo em tempos de grave crise econômica e elevado desemprego, persiste a categoria médica na situação de não ter nenhum profissional desempregado. Sem colocá-lo em grau superior a nenhum outro profissional, há uma questão concreta de sua oferta escassa e com formação longe de ser apropriada aos postulados e à prática da saúde no sistema público. A hegemonia liberal e elitista da escola médica, como regra no país, tem tudo a ver com isto. A realidade nos mostra a cada dia, o desespero de gestores para suprir as suas equipes de APS este profissional, tendo que aceitar qualquer formação ou não formação e a qualquer padrão de remuneração, comprometendo outras funções da saúde. Verdade que muitas iniciativas foram tentadas ao longo do tempo, em especial, marcante pela ousadia e volume, o Programa Mais Médicos - PMM, implementado a partir de 2013, com componente de provimento emergencial e de reestruturação profunda do currículo médico e expansão das vagas de graduação e de residência a partir de uma leitura de vazios assistenciais e de formação em todo o país. O seu apelo popular e entre os gestores por um lado, e a reação corporativa agressiva de lideranças da categoria médica por outro, mostram que, de uma forma ou de outra, com insuficiências e problemas, o programa tocou no centro da questão. Ainda é cedo para conclusões definitivas de seus efeitos, mas inúmeros estudos já foram produzidos ou estão em curso, analisando vários de seus aspectos e a tendência é de mostrar efetividade e confirmar este como um grave problema nacional.

Além da questão do volume da oferta, e talvez mais grave, é a incoerência com a formação focada na APS, que tem necessidade de um grande número de profissionais, valendo para a graduação e a pósgraduação, em especial as residências de medicina de família e comunidade. Especialidade esta que precisa ser carinhosamente cuidada pelos gestores do SUS e da Educação, não se confundido com algo como medicina geral e comunitária, clínica geral ou até médico sanitarista. Enfim, a questão da provisão, da fixação e da adequada formação médica para a APS é uma agenda permanente e a recente iniciativa do novo programa, Médicos pelo Brasil, precisa ser adequadamente debatida em suas minúcias, para checagem de sua aderência com os princípios programáticos e legais do SUS e 


\section{DebateS E Discussões}

\section{APS em Revista}

Vol. 1, n. 3, p. 222/229 | Setembro/Dezembro - 2019

ISSN 2596-3317 - DOI 10.14295/aps.v1i3.47

Magalhães Júnior, H. M.

sua efetividade. Principalmente o dilema de se provimento permanente destes profissionais em regiões rurais remotas, em distritos sanitários indígenas e na periferia das grandes cidades.

Junto deste, o segundo tema relacionado às pessoas que dão vida cotidiana à APS no SUS: o trabalho multiprofissional da equipe de saúde. Ter iniciado a estratégia de saúde da família com o formato de equipe e não simplesmente de médico de família, como alguns de nossos sistemas inspiradores, principalmente Reino Unido e Cuba, foi uma acertada iniciativa do SUS nos seus primeiros passos. E hoje, com a predominância epidemiológica das doenças crônicas e um número cada vez maior de idosos, seus efeitos e necessidades de cuidados complexos ao longo da vida, cada vez maior, exige o cuidado multiprofissional que, além de efetivo, é mais eficiente. A própria experiência brasileira com a ampliação da equipe da APS, para além do formato original de composição com médico, enfermeiro, técnico de enfermagem e agente comunitário de saúde, para outros profissionais organizados a partir dos NASF - Núcleo de Apoio ao Saúde da Família, já tem evidências suficientes para sustentar o acerto destas iniciativas. Claro que pode e deve ser aperfeiçoado este papel de apoio matricial, também com a entrada efetiva cada vez mais no plano individual de cuidado, compartilhando a atenção direta aos usuários.

Esta tendência vem sendo timidamente seguida pelo setor privado, no plano ambulatorial e no hospitalar, este com mais tradição de trabalho multidisciplinar com resultados positivos. A implantação dos NASF e com financiamento específico federal, sempre foi uma demanda dos municípios brasileiros que desde muito tempo já trilhavam com recursos próprios este caminho de formato de equipe da APS. Nos últimos anos houve uma expansão vigorosa destes núcleos com a absorção de milhares de profissionais de saúde, com vários estudos sustentando sua efetividade. Um olhar avaliativo sobre esta questão precisa ser feito neste momento em que alguns textos documentos oficiais vindos do MS simplesmente desconhecem o assunto equipe matricial ou NASF.
O terceiro desafio é a permanente agenda de (re)organização do modelo de atenção e organização da rede de serviços, com cada equipe de APS, no seu território e uma população sob sua responsabilidade sanitária. Olhando para dentro da unidade, a questão é encontrar formas de organizar as práticas cotidianas da equipe, distribuí-las ao longo do tempo dentro do horário disponível, considerando a resposta às demandas que chegam espontaneamente, importantes para efeito de atendimento direto aos usuários e relevante do ponto de vista de legitimidade da APS como principal porta de entrada na rede de serviços. $E$ considerar também a necessidade das ações programáticas ou programadas sobre grupos ou indivíduos segundo observação do seu risco. Esta discussão vem de muito tempo, tem sido cumulativa a partir de várias experiências diferenciadas em milhares de municípios, com ênfases a certos aspectos variando com o tempo e buscando sempre o melhor jeito de se organizar para cumprir o seu papel. Diversos estudos mostram que a APS vem se expandindo em equipes e unidades, assumindo cada vez mais o papel de principal porta de entrada do SUS. Isto tem a ver com investimentos em infraestrutura, ampliação de equipes, maior escopo e abrangência de atuação, incorporação de mais tecnologia local, relação mais harmônica e diferenciada com os demais pontos de atenção da rede de serviços, que tocaremos a seguir, e emponderamento cada vez maior da APS pelos próprios gestores.

No ambiente interno da unidade de APS, é o pensar e agir no cumprimento dos princípios do SUS. Primeiro, radicalizar a universalidade, com garantia real de acesso ou seja, pela facilitação de posição geográfica das distribuição física das unidades e, neste caso, a proximidade com a população no território é uma condição de êxito, ao contrário de outras tipologias de serviços, como as urgências, as especialidades e a atenção hospitalar, em que o sistema de transporte ágil e seguro é mais importante do que a posição física. Acesso também no sentido de encontrar acolhimento e escuta qualificada sempre que o usuário procurar a unidade, ter espaço na agenda da equipe para atender aos casos agudos ou crônicos agudizados. 


\section{DebateS E Discussões}

\section{APS em Revista}

Vol. 1, n. 3, p. 222/229 | Setembro/Dezembro - 2019

ISSN 2596-3317 - DOI 10.14295/aps.v1i3.47

Magalhães Júnior, H. M.

Facilitar agendamento dos retornos necessários aos planos de cuidado estabelecidos, encurtar distâncias e tempos na atuação, quando necessária, de cada membro da equipe, se responsabilizar pela concretização dos encaminhamentos a outras unidades quando necessário, priorizando os mais graves e mais vulneráveis. Isto significa pôr em prática ao mesmo tempo os princípios da igualdade/equidade e da integralidade dita necessária.

Alguns compromissos sanitários precisam ser explicitados, não só a partir da publicização, necessária, da carteira de serviços da unidade, mas certos signos praticados, como o que nenhuma criança pode sair da unidade sem sua carteira de vacinação checada, venha por qual motivo vier, nenhum diabético é atendido por alguém da equipe sem sua glicemia ser checada e seu pé examinado, ato simples e de exemplar importância e que deve ser feito por todos os membros da equipe não só pelo médico ou enfermeiro. $E$ os atributos da abrangência e escopo vão sendo progressivamente ampliados com a incorporação de tecnologias já disponíveis e testadas, e que precisam cada vez mais de apoio de financiamento, como prontuário eletrônico de uso multiprofissional, os mecanismos diversos de telessaúde, o uso de equipamentos simples para apoio diagnóstico de uso local como eletrocardiograma, testes rápidos de patologia clínica cada vez mais disponíveis, baratos e sensíveis, apoio terapêutico como nebulizadores, hidratação venosa, analgesia mais potente, micronebulização e por aí vai.

Além disto, o planejamento de ações proativas junto a populações de risco conhecidas, de novo a grande questão dos crônicos. A partir de uma varredura no território, no conhecimento de sua população usuária com relação a fatores de risco conhecidos e estandardizados, a elaboração de planos terapêuticos singularizados com vistas à prevenção secundária, terciária e quaternária e, mais importante, a intervenção na qualidade de vida dos pacientes. Apenas cerca de $5 \%$ dos doentes crônicos respondem pela maioria das demandas às unidades e isto pode muito bem ser mais bem gerenciado e se tornar efetivo com o diagnóstico clínico e de risco e o plano de cuidado individual. Também, o olhar mais coletivo para parcelas das comunidades e as famílias, em seus diferentes formatos, como forma de utilizar de intervenções coletivas para fins de redução de risco individual e melhoria de qualidade de vida. Interagindo também com atores de outras políticas públicas. Como exemplo, a epidemia de obesidade, adulta e infantil, a um só tempo doença estabelecida e fator de risco para várias outras doenças, exige atuação multiprofissional qualificada, com intervenção no ambiente familiar e nas escolas e sinergia com outras políticas públicas da assistência social, segurança alimentar, educação, cultura e esportes. O mesmo vale para a temática da violência doméstica, contra as mulheres e as crianças, a epidemia de dependência ao álcool e outras drogas e às violências urbanas, tão graves principalmente para os jovens, negros e os habitantes das periferias.

Para fora dos limites das unidades de APS, o desafio de concretizar a integralidade necessária, na continuidade do cuidado ao longo da vida, circulando por outros pontos de atenção na chamada RAS - Rede de Atenção à Saúde, constituída por unidades de atendimento de urgências e emergências, os serviços de atenção pré-hospitalar, unidades de especialidades, serviços de apoio diagnóstico, serviços hospitalares, unidades específicas de saúde mental, de assistência obstétrica e neonatal, centros de cuidado para pessoas com deficiência, centros de cuidado-dia e de assistência farmacêutica. Com ferramentas e tecnologias já testadas de regulação assistencial, com sistemas de logística e transporte adequados, com desenho das responsabilidades de cada serviço pactuadas e de conhecimento de todos, com plano de monitoramento e avaliação deste circular na rede, com empoderamento da APS para ordenar como prioridade estes encaminhamentos de seus usuários, com retorno garantido da informação em diferentes formatos, há chance grande de garantia da completude da integralidade, do atributo da longitudinalidade e coordenação do cuidado, ou, mais com sentido prático, de co-coordenação do cuidado. Para driblar os sucessivos "nãos" recebidos, os usuários 


\section{DebateS e Discussões}

\section{APS em Revista}

Vol. 1, n. 3, p. 222/229 | Setembro/Dezembro - 2019

ISSN 2596-3317 - DOI 10.14295/aps.v1i3.47

Magalhães Júnior, H. M.

constroem seus mapas de cuidado e vão seguindo na vida na busca pela atenção nos diferentes serviços.

A ideia forte de rede articulada é mostrar e garantir determinadas trilhas para facilitar esta busca pelo cuidado e pela satisfação de suas necessidades. Adiciona racionalidade ao sistema e economia no seu desempenho. Todas as experiências distintas, mais ou menos abrangentes, apontam neste sentido. Muitas das medidas sem incremento adicional de recursos, mas melhor utilizando dos já disponíveis. Esta uma agenda em aberto, iniciativas dos últimos anos do MS na sua indução mostraram seus efeitos, incluindo mais racionalidade no plano de expansão de serviços mais complexos que exigem maior densidade tecnológica e de maior população de referência. Enfim, uma breve agenda de desafios inconclusos, mas muito estimulantes para o SUS e a APS e com fins de estimular o debate e os avanços de conhecimento e da prática, bom estímulo para a jovem Rede de Pesquisa da APS. 


\section{Debates e Discussões}

APS em Revista

Vol. 1, n. 3, p. 222/229 | Setembro/Dezembro - 2019

ISSN 2596-3317 - DOI 10.14295/aps.v1i3.47

Magalhães Júnior, H. M.

\section{ABSTRACT}

Article prepared from a conference held at the 1st Workshop of the APS Network 2019, in March 2019 at FACE / UFMG, which made balance of the trajectory of Primary Health Care (PHC) and much less the Unified Health System (SUS) in its advancement after the 30th anniversary of the Federal Constitution of 1988. To address the current challenges of PHC, it was necessary to quickly review this journey until the present time. The implementation of the SUS, since its first steps, was concomitant with a new role for Brazilian municipalities, also born as federated entities in the same Constitution, and with the expansion of health care coverage, especially of primary care, already underway since the pre SUS movements.

Keywords: Primary Health Care, Public Health, Financing Health Care. 